\title{
Norbert Wetzel
}

\subsection{THE CHANGING MISSION OF HUMAN RESOURCES MANAGEMENT}

\begin{abstract}
Summary: Academics and HR practitioners are divided on the question whether the so called "best practice" approach or the "best fit" approach to designing and executing HRM policies, programs and practices will provide better results. The purpose of the paper is to reach a conclusion which will guide HRM leaders in their choice between the two approaches to human resources management. The paper discusses the issues involved and then presents a case for an approach to Human Resources Management (HRM) which is based on aligning HRM policies, programs and practices to the strategy of the organization served, its culture, its external and internal environment and its technology of production and on aligning the different elements of HRM programs and practices to each other, using the "best fit" principle. Based on evidence derived from the case histories of major companies in the recent past, the paper will demonstrate that only this approach to HRM will add value to the organization served and will provide it with a competitive edge which is something the traditional "best practices" approach to HRM is not capable of doing. The paper then explores the difficulties of simultaneously achieving alignment to the environment together with consistency of HRM policies, programs and practices and the circumstances under which this is possible. Global organizations face a special challenge in this respect and the paper explains why this is the case. Lastly, a case is presented for the need to manage with metrics and the role the so called HR Scorecard can play in measuring effectiveness of HRM activities.
\end{abstract}

Keywords: Best fit, alignment, consistency, globalization, metrics

\section{HRM AND ORGANIZATIONAL SUCCESS (OR FAILURE)}

Human resources are key to organizational success or failure. "There is a fast-growing and high-quality body of empirical research demonstrating that HRM policies have an impact on organizational performance" (Baron and Kreps, 1999, p. 4). "There is strong evidence that what are called High Performance HR Practices, such as employee recruitment and selection procedures, incentive compensation, performance management systems, and extensive employee involvement and training can improve many outcome measures, such as productivity, product quality, and innovative work practices" (Eichinger et al. 2004, p. 48).

Based on the available empirical research and evidence, we can be convinced that "organizational success with poor HRM policies is impossible, and that the effects of improved HR policies on organizational success are potentially enormous" (Baron and Kreps, 1999, p. 4).

The issue which needs to be addressed, however, concerns the specific HRM policies, programs and practices which will bring about success or failure. What needs to explored is whether there exists a body of leading edge HRM policies and practices which will serve any organization well at all times and which will be effective no matter what the organization's culture and business strategy may be or whether HRM policies and practices should be tailored to fit in the broader context of what the organization is trying to do (Baron and Kreps, 1999).

\section{THE TRADITIONAL APPROACH TO HUMAN RESOURCES MANAGEMENT}

Traditionally, HRM has been looked at as a provider of fairly mundane services: staffing the organization, deploying and redeploying employees, making sure those employees would 
be properly paid, training and developing those employees, managing industrial relations, etc. The different nature of those services gave rise to the organization of Human Resources work along process lines. Typically, HRM work would be organized by process and HRM units would provide the following services to the organizations they served:

- Workforce Management (recruitment and selection, deployment and redeployment, retention of best talent, downsizing and restructuring)

- Compensation and Benefits

- Performance Evaluation and Performance Management

- Career Management, Training and Development

- Safety and Wellbeing

- Employee Relations and Industrial Relations

- HR Research and Controlling

This process approach to organizing HR work remains unchanged until today. What has changed, however, is the understanding of how those processes should be designed and executed. The traditional thinking was that if the major HR processes were of a leading edge nature or at least "state of the art", then HRM would do its job and serve the organization well. Accordingly, one would attempt to design those processes based on what was considered "best of breed", but without much regard for the organization's culture, its business model and strategy and without much consideration for the internal and external environment in which the organization operated. The approach was to benchmark HRM policies and practices against the outside and to adopt what was considered "best practice" for the organization's own use. HRM seminars, symposia and other events served and still serve exactly that purpose: making HRM professionals and managers familiar with outstanding best HRM practices and allowing participants to copy or imitate those best of breed programs and practices. When doing this, it was and still is believed in some circles, the organization would have leading edge HRM policies and practices which would best serve the interests of the organization.

\section{WHY THE TRADITIONAL APPROACH TO HRM IS NO LONGER WORKING}

This "best practice" approach described under 2. above may have had its merits in former times when the internal and external environments were fairly stable, economies not in constant turmoil, technological progress slow and culture change rare and in any case slow. In today's world, however, where change is continuous, its pace is accelerating and the need to adapt to changes in the environment is urgent, a stable set of HRM policies and practices will no longer serve the best interests of an organization. Nor will HRM policies and practices resulting from adopting "best of breed" practices of other companies contribute to the success of an organization.

IBM's recent history is a good case in point. In the sixties, seventies and eighties of the last century, IBM was widely admired for its HRM policies and practices and was considered a leader in the filed. Full employment without regard for the ups and downs of the company's fortune in the market place, a lead policy of compensation, extremely generous benefits and, more generally, entitlement-based pay practices, were corner stones of those policies. Together with the belief in "respect for the individual", those policies were intended to be immutable and remain in place forever. As it turned out, those policies served the company well in times when it had a near monopoly in the market, but proved to be disastrous in the early nineties when the company's fortunes changed and the need for large-scale restructuring arose. Rather than do the necessary and lay off employees no longer needed, cut down on oversized pay and benefit packages and, more generally, change the entrenched culture of entitlement, executive management clung to the old policies and risked bankruptcy. The rest 
is history: the board forced out old management, brought in a new CEO from the outside who then brought about the necessary changes in HRM (and other) policies. Observers of the IT industry are convinced that this is what saved IBM from extinction.

IBM's history reminds us of an important fact: HRM policies and practices must "fit" the firm's strategy and its culture and must be attuned to the internal and external environment. In a world that is undergoing rapid change, this need to continually adjust HRM policies and practices is an important ingredient of success.

\section{WHEN HRM POLICIES AND PRACTICES WILL "FIT"}

\subsection{ALIGNMENT}

Above all, HRM policies and practices must fit in the broad context of how and where and under what circumstances a firm operates and what it is trying to accomplish. Michael Porter as cited by Baron and Kreps (1999) has identified five factors, which are of importance in this context:

- The social, political, legal and political environment

- The workforce

- The organization's culture

- The organization's strategy

- The technology of production and organization of work

Another way of describing and defining the environment is to distinguish between the external environment, i.e. the economy, the political landscape, industry dynamics, labor markets and country cultures, and the organizational environment, i.e. technology, company culture and business strategy (Jackson et al., 2009). The external environment should be seen as a set of constraints and opportunities that can influence the way an organization manages its human resources, while the components of the internal environment provide an immediate context for managing human resources (Jackson et al., 2009).

Numerous examples of how context will affect HRM policies and practices come to mind. Here is just one which illustrates how certain pay and benefit practices will make extremely good business sense in a specific situation and little or no sense under different circumstances: the early Microsoft had a practice of combining broad-based stock option plans with fairly modest cash compensation. In the years (roughly from 1985 to 2000) when the company's stock price was "on a run", i.e. was going up year after year, this was an excellent way of rewarding employees, retaining the best talent, aligning employee and shareholder interests and saving cash compensation costs at the same time. Later, when the stock moved sideways for many years, those same compensation and benefit practices no longer made good business sense and, had they been continued, would not have achieved their intended purpose. Consequently, Microsoft had to change its compensation practices and had to increase cash compensation for its employees in a significant way.

The automobile industry in the United States and its changing fortunes over time provides another good example of the need to adapt HRM policies and practices to the external environment. The recent history of General Motors, Ford and Chrysler clearly demonstrates the need to be aligned to changes in the external environment. One remembers the time when the US automobile market was dominated by three companies, i.e. General Motors, Ford, and Chrysler. Basically, those firms had the market to themselves which gave them the power to set prices. In this easy competitive environment, management would time and again give in to the demands of their respective unions and accept benefit levels and restrictive workplace rules and practices affordable at the time but which turned out to be a millstone around the 
companies' necks later when the competitive landscape had changed. A few specific examples will illustrate this point:

- It is estimated that in 2009, at the height of the crisis that engulfed the US automobile industry, each car produced by General Motors in the United States was burdened with additional costs of US \$1,000 resulting from expensive health and retirement benefits for the General Motors workforce. Ford and Chrysler were faced with a similar situation.

- Ford's contract with the union in the 2000s allowed workers nine (!) unexcused absences from work in 18 months before they could be dismissed.

- Union contracts for all the major manufacturers provided for widespread "featherbedding", i.e. work rules designed to employ workers in jobs not really needed.

Those practices gave foreign manufacturers a significant cost advantage and allowed them to compete aggressively when markets opened up. Foreign manufacturers enjoyed those significant cost advantages not only when producing cars at home but also when they set up manufacturing plants in the US. Those foreign "transplants" were either not unionized and where they were, management would stand up to the unions and resist excessive benefit levels and restrictive work place rules and practices.

As a result of all this, foreign automobile manufacturers, above all those from Japan, were able to successfully establish a market presence in the United States. General Motors, e.g.,

saw its market share of light-vehicle sales plunge from roughly $45 \%$ in the 1980 s to less than $20 \%$ in the 2000s. This long slide in market share for General Motors went hand in hand with a rise in Toyota's share from next to nothing in the 1980 s to close to $15 \%$ in the 2000 s. When this happened, established pay and benefit levels of the traditional US automobile manufacturers became unaffordable and local manufacturers had to make major efforts to reign in costs by renegotiating contracts with their unions, cutting back on excessive benefits, reducing hourly pay, etc. Long-established pay and benefit practices went over board and work rules and regulations underwent significant change. A classic demonstrating is the need to either align to the external environment or risk survival!

Here is one more example closer to the home of the author: the recent history of Austrian Airlines, Austria's national carrier. Austrian Airlines' workforce had extracted attractive employment terms and conditions from the company's management over the years, terms and conditions which were affordable as long as the airline was competing against other national carriers who had similar pay and benefit levels. But with the emergence of low cost carriers, the firm's business model built on providing high-class service at high prices turned out to be no longer viable. The result were years of significant losses, the fire sale of the company to Lufthansa and, at long last, new management which decided to take on the union and bring about major changes to pay and benefit levels in order to secure survival in an increasingly competitive environment.

\subsection{CONSISTENCY}

Not only must HR policies and practices be aligned to the organization's strategy, its culture, its environment, its workforce and its technology, HR policies and practices must also be internally complementary or at least consistent. Ideally, they must support each other, lend strength and meaning to each other and will reinforce themselves that way. As a minimum, however, HR policies and practices must not clash with each other.

Following Baron and Kreps, there are three aspects of consistency:

- Most importantly, the different policies and practices making up an organization's HRM system must be internally consistent, meaning they must be aligned to each 
other. They should emphasize (or deemphasize) the same themes and messages and must be based on the same basic view of man. If that view is that what makes employees tick is money and status, then this view must be reflected in the company's recruitment policies, its compensation practices, in the way performance is recognized and rewarded, in the way employees are developed and promoted, etc. And if the view is that what really matters is the psychological bond which holds employees and the organization together, then the entire set of HR policies and practices must emphasize this "we are one family" theme. With Baron and Kreps, we refer to this kind of consistency as "single-employee" consistency, meaning that "the different pieces of HR policy that bear on a single employee should be consistent with one another" (Baron and Kreps, 1999, p. 39).

- Consistency also means that different employees or employee groups should be treated the same way in similar situations. This is referred to as "among-employee" consistency (Baron and Kreps, 1999). As a minimum, employees working side by side, doing similar work, should enjoy the same employment terms and conditions.

- Lastly, there is a case to be made for a certain degree of consistency over time, i.e. temporal consistency or continuity.

A few more thoughts on the three different aspects of consistency are in order and are presented below.

\subsubsection{Single-employee consistency}

This is the most important aspect of consistency. Unless the various pieces of the HRM system really "fit", HRM will not contribute to the success of the organization. A couple of examples will illustrate why this is so:

- An elaborate performance evaluation system will make little or no sense if it is not complemented by compensation practices which emphasize performance, i.e. make sure that there is significant pay differentiation based on individual or team performance. Likewise, staffing decisions, i.e. decisions on who is allowed to stay, who will be promoted, who will be terminated, must be performance based. In addition, training and development must have a strong link to performance. If an organization does not promote people on merit, if it does not differentiate pay based on merit, if it does not terminate those who do not perform, why evaluate performance in the first place? On the other hand, if all the proper links between the pieces of the system are in place, an organization can credibly live a performance based culture and will derive significant benefits from that. In the absence of those links, any reference to performance as an important theme will remain mere lip service.

- Organizations should also be consistent when deciding whether they will focus on individual or team performance. When it is individual performance, then this principle must not only be observed in assessing performance but also when making pay decisions and when deciding on promotions. They must also decide whether the emphasis is on egalitarianism or meritocracy, on centralization or decentralization, trust or distrust in relations between the firm and its employees, focus on outcomes (getting the job done) or process (following rules), etc. (Baron and Kreps, 1999). Only to the extent that an organization sends "unambiguous and consistent messages to its employees about these topics, employees will have a clearer and more powerful sense of what they can expect and what is expected of them, thereby aiding in the attraction, motivation, and retention of people best suited to the enterprise" (Baron and Kreps, 1999, p. 43). 


\subsubsection{Among-employee consistency}

This kind of consistency is highly desirable because it touches upon basic notions of fairness and equity. In its most rudimentary form, among-employee consistency means that employees working side by side should enjoy the same terms and conditions, meaning they should have the same or similar pay, be covered by the same benefits, enjoy equal job security and be subject to the same rules and regulations governing all aspects of employment. This principle of among-employee consistency is as important in principle as it is difficult to achieve in practice. The reasons for this difficulty are many-fold:

- There has been a paradigm shift in how and on what legal basis people are employed. Full-time regular employment is no longer the norm but becoming the exception in many organizations. As a rule, full-time regulars are complemented by part-time employees, temporary employees, contract personnel, agency and vendor personnel, consultants and employees in subsidiaries, joint ventures and affiliates of some sort. When and where this is the case, employment terms and conditions are likely to differ. After all, different employment models are often used precisely because they allow the use of different terms and conditions and will result in cost savings for the enterprise. Where this is the case, charges of unequal treatment and discrimination are likely to arise and teaming between employees belonging to different groups will take a toll.

- Among-employee consistency is also affected by the way global companies manage their business. Increasingly, they will manage their business as a portfolio of businesses and will divest selected business areas when needed just as they will invest in new business areas on an ongoing basis, resulting in increasing resource dynamics with significant population churn. Among other things, this means that when investments are made in new business areas, employees with different terms and conditions must be absorbed and integrated. This takes time and different terms and conditions are likely to persist for extended periods of time. Within the EU, the Acquired Rights Directive (Directive 2001/23/EC) even aims to ensure that in case of the "transfer of an undertaking" the terms and conditions of employment are maintained for the employees affected. This will virtually guarantee that amongemployee consistency does not exist, at least for a period of time.

- Lastly, among-employee consistency is difficult to achieve for global companies who need to align their HRM policies, programs and practices to the different local environments of the many places where they operate. This issue will be addressed more fully under Chapter 5 below.

Almost needless to say, in the absence of among-employee consistency, creating and maintaining a motivated workforce committed to the organization's goals and values represents a significant challenge.

\subsubsection{Continuity}

Continuity in the sense of consistency over time is another important aspect of consistency. Employees should be subject to a stable set of HRM policies and practices because sudden and frequent changes create ambiguity and will leave employees confused and unable to understand what is expected of them. But it is obvious that consistency over time can conflict with the need to change HRM policies and practices in response to changes in the organization's strategy, its culture, its environment, or its technology of production. The challenge any organization will have is to strike the right balance between the need for continuity and the need to make the necessary changes. 


\subsection{ALIGNMENT AND CONSISTENCY - CAN WE HAVE BOTH?}

As has been pointed out, HRM policies, programs and practices should ideally be aligned to the external ands internal environment and should also be consistent with each other ("single-employee consistency"), among employees ("among-employee consistency") and over time ("continuity"). In an organization faced with a uniform external environment, as would be the case if operations were restricted to a single country, achieving this kind of alignment together with consistency in all of its three dimensions is not necessarily guaranteed but will often be possible if the necessary effort is made. Alignment to the environment is always important and so is single-employee consistency. Difficulties may arise where alignment to the external environment requires the different treatment of employee groups, as pointed out under 4.2.2 above, or where alignment to the external and internal environment requires making changes to HRM policies, programs and practices and thus abandoning continuity. Clearly, a trade-off is required between the need for being aligned to the environment and the desire to have continuity. Overall, however, achieving alignment together with consistency in all its aspects is easier when an organization operates in a single environment rather than being faced with a multitude of different environments. When an organization does business in many countries and cultures, however, as is the case with global companies, there are manifold external environments to deal with and achieving alignment together with consistency presents a much bigger challenge. The impact of globalization will now be explored below.

\section{HRM AND GLOBALIZATION}

Alignment of HRM policies, programs and practices and their consistency as described above are the corner stones of effective Human Resources management. What needs to be explored is how alignment and consistency are impacted by globalization.

Globalization has many aspects. For the purpose of this paper, a global company is defined as a company, which serves customers and clients in different parts of the world, and has presence in different parts of the world (presence being defined as owning assets and employing people), sources products, parts and components from around the globe and, lastly, also sources talent for professional and managerial positions from around the globe.

Managing human resources in this kind of company poses some very special challenges which will now be explored.

It will be remembered from 4.1 above that alignment of HRM policies, programs and practices is about making sure they are in tune with

- The social, political, legal and political environment

- The workforce

- The organization's culture

- The organization's strategy

- The technology of production and organization of work

While a global company will attempt to establish the same organizational strategy and the same technology of production and organization of work wherever it has a presence, it is obvious that the external environment, i.e. the social, legal and political environment, will show significant differences around the globe. Also, the local manifestation of the organization's culture will always be impacted by the local culture. Typically, one can observe the emergence of a hybrid organizational culture, made up of elements of the global company's corporate culture and the local culture.

Given that situation, a global company will have a choice between being fully aligned to the various external environments where it operates, in which case consistency of HR 
policies, programs and practices will be impacted, or to have consistency of HR policies, programs and practices across all locations where it operates and, as a result, sacrifice or at least compromise alignment to the external environment.

Another way to describe the dilemma, which global companies face, is to introduce the concept of "fit" in global HRM. "Internal fit is concerned with making sure that HRM policies facilitate the work values and motivations of employees. Policies must be structured in ways that allow headquarters and foreign subsidiaries to interact without sacrificing efficiency. External fit, on the other hand, refers to the degree to which HRM matches the context in which the organization is operating. ... To be effective, the organization must understand the cultural and socioeconomic environments of the foreign subsidiary." (Ivancevich, 2007, p.101). The disturbing fact is that it is difficult if not impossible to achieve a high degree of external fit together with a high degree of internal fit. What global companies face is a situation where they must trade off external fit against internal fit. Or, to quote Baron and Kreps, "the trade-off, of course, is between consistency in HR strategy and practices across units versus fitting those strategies and practices to specific situations" (Baron and Kreps, p. 519).

How a global company will make that choice will depend on many considerations. One thing is clear: there is no standard solution; the choice will have to be made in each individual case, after having answered the following question: "What are the costs of potential inconsistencies in policy and practice across parts of the organization; and what are the benefits of customizing HR activities to the particular context?" (Baron and Kreps, p. 520). When trying to answer that question, it will be helpful to identify those factors which favor consistency of HR policies, programs and practices, and also those factors which speak in favor of customizing HR practice to the local environment.

\subsection{CONSIDERATIONS IN SUPPORT OF CONSISTENCY}

We will expect to see a high degree of consistency in the following situations:

- When the global company has a global line of products and/or services and when the company's globalization strategy is "predicated more on developing global brand equity and facilitating the transfer of knowledge, products, and technologies from one business unit or locale throughout the organization, particularly when the client or customer being served is itself a global enterprise (Baronand Kreps, 1999, p.520)

- When the company's RandD facilities and its manufacturing operations are closely interrelated and the company's workforce must cooperate closely in product development and manufacturing.

- When the global company makes a green-field investment, i.e. starts operations in a foreign country from scratch.

- When the company has a very strong and dominating culture and the company attracts a profile of employees matching that culture.

- When the global company is dependent on foreign assignees for the management of its foreign operations and must assign personnel from headquarters or other units to staff managerial and professional positions in the foreign country.

- When HRM programs and practices have a high degree of complexity and are expensive to develop.

In a nutshell, the global company with a strong, dominating culture which serves customers or clients in a global market, sources talent from around the globe to staff its operations, has a high degree of interrelation between units, is more likely to insist on a high degree of consistency of its HRM policies, programs and practices. 


\subsection{CONSIDERATIONS IN SUPPORT OF ALIGNMENT TO THE LOCAL CONTEXT}

Conversely, we will expect to see strong efforts to align to the local context and to accept compromising consistency when the following circumstances exist:

- The company develops local products and services to serve local markets.

- The local units have a high degree of independence.

- The local units are not dependent on the parent for staffing managerial or professional positions and there is hence little or no exchange of staff between units.

- The global company has acquired local companies with an entrenched and successful culture.

- The global company's organizational culture values autonomy rather than control.

- Local country culture is very strong and the company cannot attract employees who will fully buy into the parent company's values and beliefs.

- The industrial relations environment, i.e. the relationship with unions and other employee representative bodies, such as works councils, and the corresponding legislation is such that significant modifications are needed to the parent company's mode of operations.

Again in a nutshell, the global company which is primarily serving local customers and clients in their local markets, is operating in an environment requiring substantial modifications to the parent company's mode of operations and must hence grants lots of autonomy to the local subsidiaries, will most likely compromise full consistency in the interest of alignment to the local context.

\subsection{COMPENSATION PRACTICE OPTIONS}

A good example of the options available to a global company when designing pay systems is presented by Bloom et al. who distinguish between three general compensation strategies available to companies with worldwide operations:

- The "localizer" will design and execute pay systems consistent with local conditions. Typically, the company's business strategy is to seek competitive advantage by providing products and services tailored to local customers.

- The "exporter" is the virtual opposite of the localizer. "Exporters design a total pay system at headquarters and export it worldwide for implementation at all locations. Exporting a basic system (with some adjustments for national laws and regulations) makes it easier to move managers and professionals among locations without having to change how they are paid. It also communicates consistent worldwide objectives Common software used to support compensation decisions and deployed around the world makes uniform policies and practices feasible" (Milkovich and Newman, 2005, p.522).

- Similar to exporters, the "globalizer" will "seek a common system that can be used as part of the glue to support consistency across all global locations. But headquarters and the operating units are heavily networked to share ideas and knowledge" (Milkovich and Newman, 2005, p.522, 523). This policy option tries to combine the advantages of consistency across all locations with the advantages of at least partial alignment to the local context, the latter being achieved by using networking with the operating units and relying on their input when designing the common pay system.

Needless to say, no one of those options can achieve full consistency and perfect alignment to the local context. There is always the need for a trade-off between the two. 


\section{THE NEED FOR METRICS AND AN HR SCORECARD}

In addition to the improved understanding, today we have need to have HRM policies and practices aligned to the organization's strategy and environment and to have consistency of those policies and practices, there is now a much better understanding of the need to have a meaningful set of metrics which must guide the work of HRM and measure HRM effectiveness.

In the not so recent past, HRM programs and practices were not believed to be subject to quantitative analysis. Rather, the belief was that management should engage in deep thinking about the kind of HRM programs and practices needed and should execute those believed to serve the interest of the organization best.

Today, it is increasingly understood that metrics can play a very useful role and can be "used to evaluate the effectiveness of the organization's many HR policies and practices" (Werner et al., p. XVII). Metrics will track the progress HRM is making in delivering value to the organization and will answer the questions whether specific HRM programs will do what they were designed to do. A few simple examples will illustrate this point:

- It is often claimed that the grant of stock options will help retain key employees. It is also claimed that stock options will align the interests of managers who receive option grants with the interests of shareholders. Based on this belief, many companies have implemented stock option programs. Simple metrics could be used to substantiate (or refute) those claims. One could simply compare the attrition rate (turnover rate) of employees with and without stock options and one will have a much better understanding of what stock options will do to retain a company's best talent. Likewise, comparing the financial performance and stock market performance of companies with and without stock option programs will allow us to make a judgment about the effectiveness of the claimed alignment of interests.

- Simple metrics could also be used to establish how effective different recruitment and selection methods are. Comparing the on-the-job success of employees recruited from different sources or the job success of employees selected by different recruiters will provide the answer.

- Metrics are also useful to track the efficiency of an organization's HRM programs and practices, using simple productivity measures. One could track the development of those measures over time and/or could use them to benchmark the organization's productivity against the outside.

More recently, the work on metrics has evolved further and resulted in the use of a socalled Balanced Scorecard, a combination of hard and soft measures. This has been extended into the HR Scorecard to measure the accomplishment of all of the above (Eichinger et al., 2004).

With the increasing popularity of benchmarking, companies now increasingly will compare themselves to other firms in terms of their turnover rates, HR headcount and costs per capita, training costs per employee, or employee satisfaction (sometimes by hiring an outside firm to do the survey and provide comparison statistics on comparable firms)" (Baron and Kreps, 1999, p. 526). Such efforts are useful, but a few caveats are in order:

- Comparisons can be useful, but in order to be meaningful, they should be limited to the firm's own industry.

- Even within the same industry, comparisons are only meaningful, if $t$ he firms compared pursue similar strategies and use comparable technologies.

- Most meaningful are HR-related metrics which track the firm's performance over time. 
- HR-related metrics "tend to be less precise than performance standards in other domains such as those that concern costs, market share, or operational efficiency." (Baron and Kreps, 1999, p.526). Holding managers accountable for such metrics is difficult under those circumstances, but if managers are not held accountable, they will disregard those metrics.

According the Baron and Kreps, the solution is to develop so called "HR drivers" of the business: "What are the specific facets of human resource management that translate into tangible business outcomes that the organization cares most about by virtue of its strategy? Then, having identified those HR drivers, organizations should develop metrics that permit line managers and the HR function to be assessed in terms of the quality and cost of their efforts to develop and maintain the key HR drivers" (Baron and Kreps, 1999, p.526, 527).

\section{CONCLUSIONS}

There are a number of simple truths which emerge from the observations made:

- The "best fit" approach to HRM is far superior to the "best practice" approach. Best fit means aligning HR policies, programs and practices to the environment and making sure they are consistent with each other.

- Alignment to the environment is key factor and unless it is accomplished, a firm's survival is at stake. As the case histories mentioned show, alignment to the external environment is neglected at an organization's peril.

- Since change is pervasive in our society and its pace is quickening, timing is all important. Making the necessary changes to a company's HRM policies, programs and practices in time, and not only when survival has already become an issue, is the key challenge to a company's policy makers.

- Unfortunately, the need to align HRM policies and practices to the external and internal environment often conflicts with continuity, which is also a desired characteristic of HRM policies, programs and practices. Continuity, i.e. consistency over time is highly desirable but needs to be compromised in the interest of alignment to the environment.

- In the age of globalization, among-employee consistency represents another critical challenge. Treating all employees around the globe, the same is desirable but is often in conflict with the need to align policies, programs and practices to the local environment. One cannot always have both and trade-offs will be required.

- Metrics are useful to track the efficiency of an organization's HRM programs and practices. Even more useful is an HR Scorecard, which will measure the accomplishment of HRM's effectiveness against hard and soft benchmarks.

\section{REFERENCES}

1. Baron, J.N., Kreps, D.M. (1999): Strategic Human Resources, Frameworks for General Managers, John Wiley and Sons, Inc. New York, ISBN 0-471-07253-2

2. Becker, B., Huselid, M., Ulrich, D. (2001): The HR Scorecard: Linking people, strategy and performance. Boston: Harvard Business School Press

3. Eichinger, R.W., Lombardo, M.M., Ulrich, D. (2004): Best People Practices for Managers and HR, Lominger Limited, Inc. Minneapolis

4. Jackson, S.E., Schuler, R.S. (2003): Managing Human Resources Through Strategic Partnerships, Thomson South Western, ISBN 0-324-15265-5 
5. Werner, S., Schuler, R.S., Jackson, S.E. (2009): Human Resource Management, South Western Cengage Learning, 11th. edition, ISBN-13: 978-1-111-82232-3

6. Porter, M.E. (1985): Competitive Advantage, Free Press, New York, ISBN 0-68484146-0

7. Milkovich, G.T., Newman, J.M. (2005): Compensation, McGraw-Hill, Boston, ISBN 007-123928-6

8. Ivancevich, J.M. (2007): Human Resource Management, McGraw-Hill, ISBN 007125423-4

9. Fatima Fernandez F (2005): Globalization and Human Resource Management, HNB Publishing, New York, ISBN 0-9664286-8-4

10. M. Bloom, Milkovich, N., Mitra, A. (2003): International Compensation: Learning from How Managers Respond to Variations in Local Host Contexts, "International Journal of Human Resource Management, special issue 